\title{
Medical Images Processing using Effectiveness of Walsh Function
}

\author{
Tamilarasu Viswanathan ${ }^{1}$, M. Mathan Kumar ${ }^{2}$ and C. Sasikumar ${ }^{3}$ \\ 1,2,3Electrical and Electronics Engineering, Kumaraguru \\ College of Technology, Coimbatore, India
}

\section{ABSTRACT}

This paper presents the new method for processing medical images using effectiveness Walsh function. The Block pulse functions is defined, and the coefficient function is developed for identifying fixations and boundary limitations. The algorithms developed for basic functions with respect individual blocks and simulating using MATLAB. Proposed scheme shows that the performance analysis is better than existing schemes.

KEY WORDS: WALSH FUNCTION, BLOCK PULSE FUNCTIONS, FUNCTION COEFFICIENTS AND FIXATIONS.

\section{INTRODUCTION}

Many techniques employed for analyzing the medical images which are not clearly indicates the solution of the specific problem. This results in development of new methods are find out to identify advantages in specific method. The individual details are analyzing as functions of unique details is identified in simple and efficient way. Many repetitive methods are involved in set of welldefined functions means of trigonometric relationship and they are only suitable in limited boundary. It is necessary to propose a fresh method for wide range of solutions. Walsh function is suitable for medical image analysis and extend for the more independent analysis is proposed in this work. The objective of the medical image representation is adjustable in frequency domain for more set of function for doing the repetitive solutions. The image analyzing comprehensively used in solving

\section{ARTICLE INFORMATION}

*Corresponding Author: viswanathan.t.eee@kct.ac.in Received 7th Oct 2020 Accepted after revision 13th Dec 2020 Print ISSN: 0974-6455 Online ISSN: 2321-4007 CODEN: BBRCBA

Thomson Reuters ISI Web of Science Clarivate Analytics USA and Crossref Indexed Journal

\section{Clarivate
Analytics}

NAAS Journal Score 2020 (4.31) SJIF: 2020 (7.728)

A Society of Science and Nature Publication,

Bhopal India 2020. All rights reserved.

Online Contents Available at: http//www.bbrc.in/

Doi: http://dx.doi.org/10.21786/bbrc/13.11/16 nondeterministic problem for wide range including the extensive properties of relating many of them. More development occurs in computational effort using hardware and software arrangement leads to solve new category of problem statements.

Generated medical test images for specific case is shown in Fig. 1. From the regular analysis, the variation in the images giving different opinion about the medical report varies with person. In general, its necessary to give detail about the small variation make huge impact on the consultation. Including the Walsh function for analyzing the functions results in better analysis and use of effectiveness is discussed. In the next section, the Walsh function and its fundamentals are examined in the view of image analysis. In section III, the image parameters are related with the Walsh function is explained. The last conclusion section details the future scope and further improvement is discussed.

Walsh Functions and its Fundamentals: A. Block Pulse Functions (BPFs) The set of block pulses represented is shown in Fig. 2 for every ith element $\mathrm{N}$ count is

$$
W_{i}(t)=1 \text {, for } i T / N \leq t \leq(i+1) T / N
$$

Where $\mathrm{N}$ is operating duration of individual pulse in seconds.

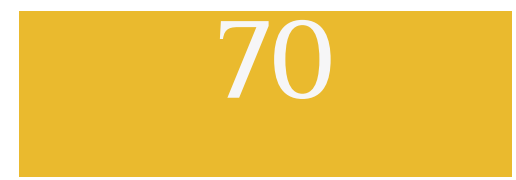


For every set, the individual components are identified through selection of operating limit. The general

function can be set as operating limit for 1 to $\sqrt{N}$. Consider the function for doing image analysis as

$$
\begin{aligned}
f(t)=\sum_{i=0}^{\infty} C_{i} W_{i}(t)= & C_{1} W_{1}(t)+C_{2} W_{2}(t)+\mathrm{L} \\
& +C_{N} W_{N}(t)+\mathrm{L}
\end{aligned}
$$

B. Representation of different combination of BPFs: The arrangement of any function is identified as individual BPF coefficient as (C1, C2...CN). Every individual sample is identifying the same $\mathrm{N}$ and $\mathrm{T}$ value for the solutions. The similarity rate identifying the flowchart shown in Fig. 3.

Figure 1: Medical Test Scan Image

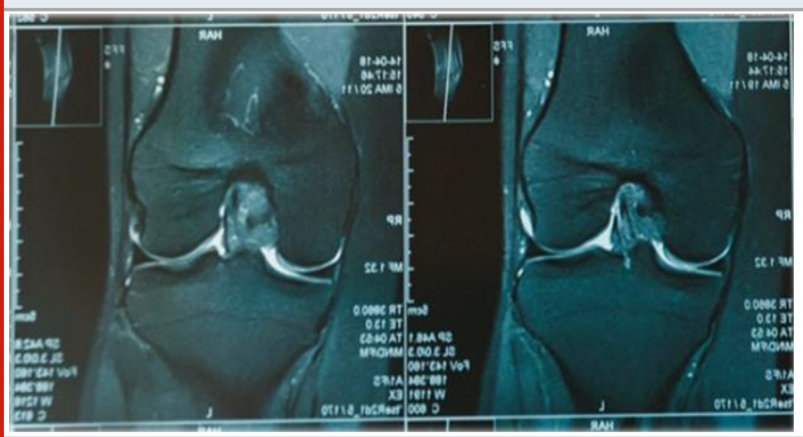

Figure 2: General Block pulse Functions with Four Weights.

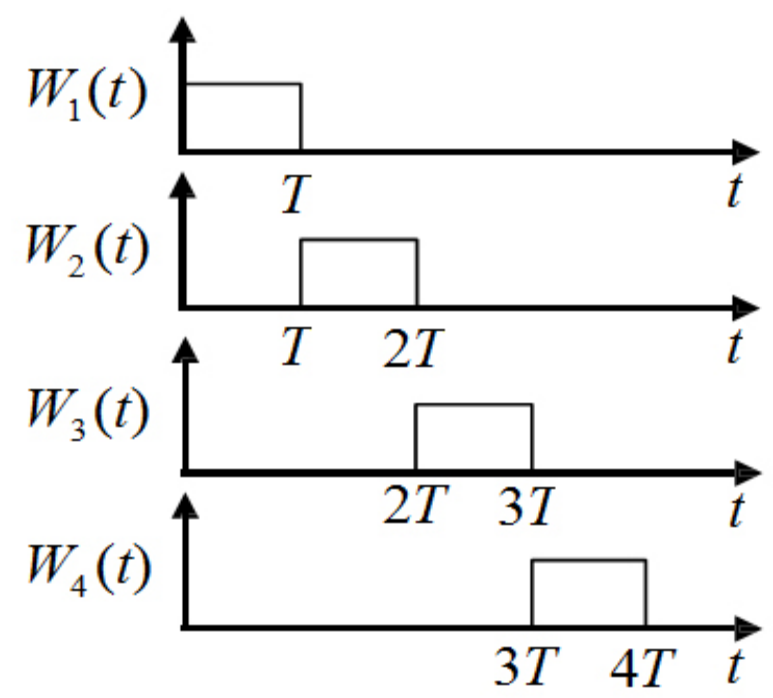

C. Fixation and Function coefficients: From the block boundaries, the limitations determined through a general form of Walsh function coefficients. They represent and explain the following conditions

1. The value should be regulated with image boundary and sample variations.
2. Comparing with existing schemes, the computational capability correctness with minimal approach.

3. The fixation and boundary to be verified for each case through necessary influences.

4. The intermediate transformations with providing the symmetrical and space variation.

5. Individual block should be combination of other adjacent blocks with general mentioning.

Figure 3

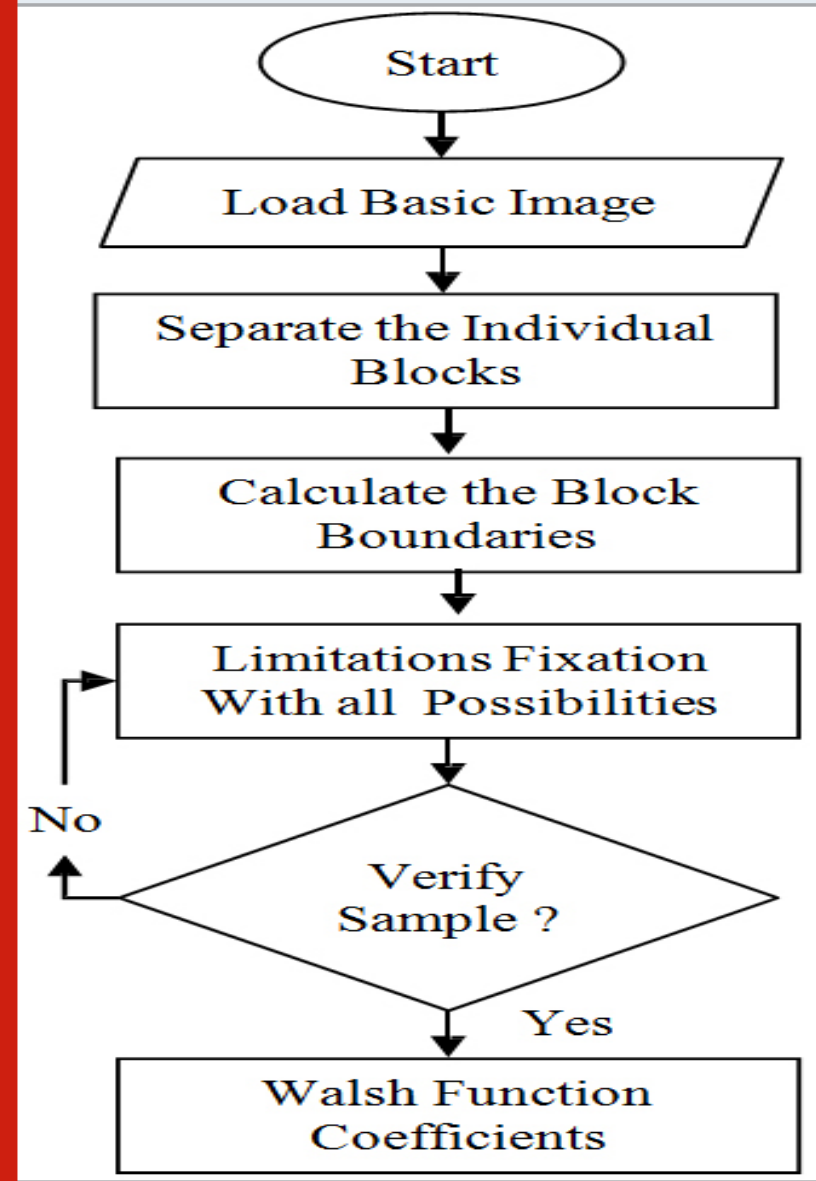

Figure 4: Walsh Transformation of Scanned image in Fig. 1

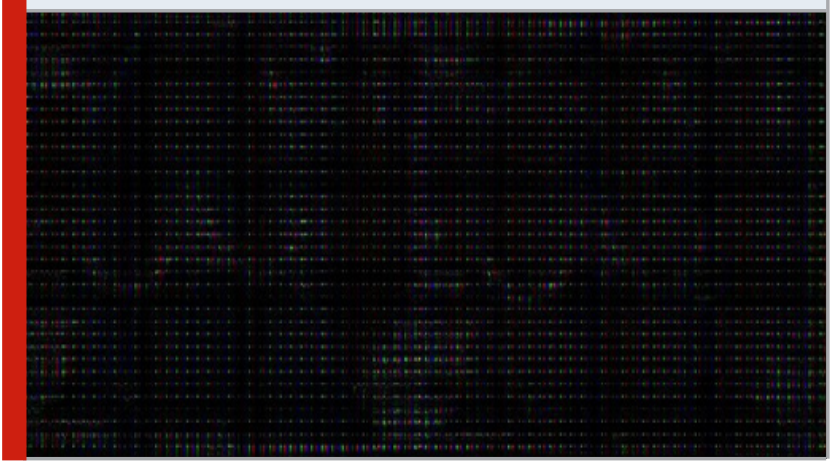

RESULTS AND DISCUSSION

The proposed scheme is developed in MATLAB using $\mathrm{m}$ file from the flowchart shown in Fig. 3. The comparison 
with existing scheme with proposed schemes is tabulated in Table 1.

Table 1. Comparision of Existing Scheme With Proposed Scheme

\begin{tabular}{|l|c|c|c|}
\hline Properties & $\begin{array}{c}\text { Existing } \\
\text { Method [2-3] }\end{array}$ & $\begin{array}{c}\text { Existing } \\
\text { Method [3-4] }\end{array}$ & $\begin{array}{c}\text { Proposed } \\
\text { Scheme }\end{array}$ \\
\hline $\begin{array}{l}\text { Block } \\
\text { separation }\end{array}$ & Not Available & Available & Available \\
\hline Limitations & Pixel Missing & $\begin{array}{c}\text { Computation } \\
\text { Effort }\end{array}$ & File Size \\
\hline Fixations & Yes & No & Yes \\
\hline Accuracy & $67 \%$ & $85 \%$ & $98 \%$ \\
\hline Depth Level & Level 2 & Level 2 & Level 3 \\
\hline Variation & Not Available & Maximum & Maximum \\
\hline Determination & $56 \%$ & $67-78 \%$ & $70-88 \%$ \\
\hline
\end{tabular}

\section{CONCLUSION}

The effectiveness of Walsh function is used for identifying the features available in medical image for consultation. The images are analyzed with MATLAB and developed a generalized function for any level. In the future, the proposed method implements with hardware for real-time.

\section{REFERENCES}

Alireza Keshavarz (2020). walsh(N) (https://www. mathworks.com/matlabcentral/fileexchange/50202walsh-n), MATLAB Central File Exchange

Arshad, U., Batool, S. I., \&t Amin, M. (2019). A novel image encryption scheme based on Walsh compressed quantum spinning chaotic Lorenz system. International Journal of Theoretical Physics, 58(10), 3565-3588.

ILambin, P., Leijenaar, R. T., Deist, T. M., Peerlings, J., De Jong, E. E., Van Timmeren, J., ... \& van Wijk,

Y. (2017). Radiomics: the bridge between medical imaging and personalized medicine. Nature reviews Clinical oncology, 14(12), 749-762.

Sneha, P. S., Sankar, S., \&t Kumar, A. S. (2020). A chaotic colour image encryption scheme combining WalshHadamard transform and Arnold-Tent maps. Journal of Ambient Intelligence and Humanized Computing, 11(3), 1289-1308.

www.ucsfhealth.org/-/media/project/ucsf/ucsf-health/ medical-tests/hero/knee-mri-scan-2x.jpg 